\title{
El Garantismo en el marco del derecho administrativo sancionado
}

\author{
The Protection of Civil Liberties in the Frame of the \\ Sanctioned Administrative Law
}

\section{Resumen:}

El presente artículo pretende evidenciar las estrechas relaciones que existen entre el Estado de Derecho y las garantías encaminadas a la protección de los derechos fundamentales de las personas, sobre todo, cuando de ejercer el poder punitivo del Estado se trata en procura del interés general, pero con la necesaria referencia de los límites estrictos al ejercicio del poder, para evitar desembocar en la arbitrariedad y el abuso característicos de los sistemas totalitarios, en los cuales se aminora el valor del hombre y se atenta contra la dignidad humana. En ese escenario se propone una tesis que propugne por la reivindicación y garantía de los derechos fundamentales y sobre todo, por la dignidad del hombre, así se encuentre sometido éste en un momento dado de su vida, bajo el sistema punitivo del Estado, circunstancia en la cual mayor protección requiere.

Palabras clave: Garantismo, Estado Social de Derecho, poder punitivo, derecho administrativo sancionador, Derechos fundamentales, legalidad.

\section{Abstract:}

This article aims at making clear the deep relationship between the State of Law and the guarantees to protect the fundamental rights of the people, especially, when it comes to exert the punitive power of the State in search of the general interest, but with the necessary reference of the strict boundaries to the exercise of power, in order to avoid resulting in arbitrariness and the abuse which are characteristic of the totalitarian system, where the value of man is reduced and an outrageous act against human dignity is committed. That is why a thesis advocating for the vindication and guarantee of the fundamental rights is proposed, above all, by the dignity of man, although he is subject to the punitive system of the State, this is the right time of his or her life when he or she requires protection.

Keywords: Protection, Social of law, Punitive Power, sanctioned Administrativelaw, fundamental rights, legality.

'Este artículo es un producto de la investigación titulada "Derecho Administrativo Sancionador Garantista - Entre el Control Social y la Protección de los Derechos Fundamentales". Fue expuesto como ponencia en el XXIII Foro Procesal de la Universidad de Medellín. Bajo el título "Garantismo cuestión de proceso y de Estado".

"Abogado, Magister en Derecho Administrativo, Candidato a doctor en Sociología Jurídica e Instituciones Políticas, Docente investigador de la Maestría en Derecho Procesal de la Universidad de Medellín. Miembro del Grupo de Investigaciones en Derecho Procesal de la Universidad de Medellín. jugarojas@hotmail.com 


\section{Introducción}

En épocas convulsionadas como las actuales, en donde es común que se hable soterradamente de la sustitución del Estado de Derecho por el "Estado de opinión", donde los medios de comunicación pretenden tener la última palabra en torno al ejercicio de la función jurisdiccional, donde muchos claman por el retorno institucional de penas y sanciones ya superadas al menos formalmente, como sería el ejemplo de la pena de muerte, donde lo que parece imponerse en términos de democracia es la democracia plebiscitaria del líder, donde la anomia de quienes detentan el poder ha llegado a extremos absurdos, y donde la impunidad y con ella la violencia campea y florece, hablar de garantismo es nadar contracorriente.

Es nadar contracorriente porque el garantismo representa la doctrina del reconocimiento y respeto de los derechos fundamentales, del establecimiento de límites al ejercicio del poder, aunque se trate del poder de las mayorías, en suma, es el vivo reflejo del Estado Constitucional de Derecho, es decir, representa un discurso contrario al totalitarismo, al absolutismo, a la dictadura, así ésta se encuentre disfrazada de democracia por la utilización instrumental del sufragio.

Hablar de garantismo implica sumergirse en las raíces mismas del Estado de derecho, su lógica, su razón de ser, es entender las razones por las cuales se dio la transición del modelo absolutista al modelo liberal del Estado de derecho, y de éste al modelo del Estado social de derecho. Por ello, el garantismo como doctrina, es ante todo una cuestión de Estado, ya que éste es de su esencia, o más bien, el Estado de derecho tiene como soporte central, la garantía de los derechos, o si no fuera así, żcuál sería entonces el papel del Estado?

Sin embargo, es preciso aclarar que la expresión garantismo, es utilizada para referirse a múltiples nociones. Por ejemplo para Ferrajoli, es un término que representa cuando menos tres acepciones a saber: en primer término el vocablo puede ser utilizado para hacer alusión a un modelo normativo, Estado de derecho y democracia. En segundo término, el garantismo representa una teoría del derecho, y por último, una filosofía política?

Pero más allá de las acepciones dadas por Ferrajoli, el garantismo puede ser abordado desde la perspectiva del derecho procesal, desde el punto de vista del derecho constitucional y en general, desde la teoría de los derechos fundamentales, por cuanto si hay algo que deba ser garantizado, en especial en estos complejos tiempos, son precisamente los derechos subjetivos ${ }^{2}$, en especial, los derechos fundamentales, que fácilmente pueden verse avasallados por quienes detentan el poder con la proclividad de manejar a su amaño el sistema jurídico, bien sea interpretándolo deliberadamente según su conveniencia, o modificándolo para su beneficio en el peor de los casos.

En ese contexto las garantías de los derechos fundamentales deben estar encaminadas a la atención de dos frentes: 
De una parte, evitar que el Estado irrumpa contra el individuo menoscabando sus derechos de libertad, es decir, sus más elementales derechos fundamentales. Allí, el garantismo se yergue como parámetro de limitación del ejercicio del ius puniendi, para evitar que el derecho sancionador bajo cualquiera de sus modalidades, sea utilizado como simple mecanismo de represión social, de retaliación y de violencia "legítima", encaminada a aminorar al individuo, a someterlo, a eliminarlo.

De la otra, propender por la consolidación y cumplimiento de los compromisos sociales del Estado, que implican una acción positiva tendiente a la satisfacción de unas necesidades vitales mínimas, requeridas para vivir en sociedad con dignidad.

Con todo, el presente escrito tiene como propósito dar cuenta de cómo el garantismo representa un discurso que debe ser tenido en cuenta en especial, cuando de establecer controles al poder se trata, en procura del respeto y garantía de los derechos fundamentales. Esto es especialmente sensible cuando se está en presencia del ejercicio del poder punitivo del Estado, máxima expresión material de poder que éste puede tener frente a los ciudadanos.

\subsection{Garantismo y Estado de derecho}

Estado de derecho no es lo mismo que Estado con derecho. Aunque algunos prefieren hablar del Estado de derecho en una doble dimensión ${ }^{3}$, en un primer término para referirse a todos los ordenamientos con independencia de que sean autoritarios o totalitarios, en los que el poder tiene una fuente y una forma legal ${ }^{4}$, en otro sentido para aludir a lo que corresponde evidentemente a un Estado de derecho, que es el que se caracteriza por la existencia del principio de legalidad, por la separación de funciones entre los distintos órganos del poder público, los controles recíprocos (que ningún órgano escape a control), por la garantía y primacía de los derechos fundamentales, por la independencia judicial y por la posibilidad de la participación popular en la adopción de las decisiones que afectarán al colectivo (representación popular).

En síntesis, la razón misma de ser del Estado está relacionada con la garantía los de derechos, nótese como desde las propias doctrinas contractualistas, su justificación está dada por la garantía algunos de ellos, por ejemplo, la seguridad (Hobbes), la propiedad privada y la libertad (Locke), derechos sociales (Rousseau), y en general, para amparar alguna categoría de derechos.

Desde una perspectiva liberal, el Estado de derecho garantiza la no intervención del Estado en la afectación de los derechos de libertad, desde una perspectiva del Estado social, a más de ello, se propende por un actuar positivo en procura de la consecución de un bienestar social.

En suma, existe una relación necesaria entre el Estado y las garantías de los derechos, pero ello se hace más evidente cuando estamos en presencia del Estado Constitucional y Social de Derecho. 
Si los derechos fundamentales son la principal razón de ser del Estado de Derecho, su papel no puede limitarse a su consagración y reconocimiento. De nada sirve si no se establecen los mecanismos para su garantía.

Ahora bien, no es lo mismo analizar el tema de la garantía de los derechos desde una perspectiva del Estado típicamente liberal, a si éstos son analizados desde una perspectiva del Estado social, toda vez que en este último caso el catálogo de derechos se amplía necesariamente por el establecimiento de obligaciones de actuar positivo.

El escenario donde con mayor claridad debe verse reflejada la garantía de los derechos fundamentales desde una perspectiva liberal es sin duda alguna, el ámbito del derecho punitivo del Estado, y en ese contexto, los instrumentos diseñados constitucional o legalmente para garantizar el amparo de los derechos de las personas, son la manifestación misma del Estado de derecho.

\subsection{La potestad punitiva del Estado en su doble dimensión.}

La potestad punitiva del Estado tiene dos facetas a saber: de una parte la potestad punitiva penal, de la otra, la potestad administrativa sancionadora.

Hablar sobre el Derecho Administrativo Sancionador por ejemplo, implica de manera necesaria referirse al ejercicio de una potestad de la administración que tiene como fundamento habilitante una construcción teórica según la cual, toda autoridad estatal para sancionar a los ciudadanos como consecuencia de una infracción administrativa o la realización de un delito, emana de su ius puniendi o poder punitivo del Estado ${ }^{5}$.

Este poder punitivo puede concebirse de diversas formas según el sistema político y la especial visión que se tenga sobre él en un Estado determinado. Por ejemplo, en algunos sistemas se ha considerado que el ius puniendi sólo puede ser admitido en la esfera de la actividad judicial, lo que implica una dimensión única del poder punitivo del Estado bajo la óptica del derecho penal $^{6}$, mientras que en otros, como es el caso colombiano, se admite sin reparos su doble dimensión, es decir, a más del ámbito penal y su aplicación por los jueces, se reconoce la esfera del Derecho Administrativo Sancionador y su utilización por parte de la administración pública ${ }^{7}$.

Sin embargo, el ius puniendi tal como es concebido en la actualidad, es el resultado de un proceso histórico que tiene sus orígenes en el "régimen de confusión de poderes característico del Estado absoluto, en el cual autoridades que hoy han devenido puramente administrativas ostentaban simultáneamente funciones judiciales de orden pena $\left.\right|^{\prime \prime}{ }^{8}$, lo cual permite aseverar que el origen histórico de esta institución se halla en una fase previa a la consolidación del Estado de derecho, en la que no se había configurado la división funcional del poder público y mucho menos, el establecimiento de parámetros legales que permitieran establecer garantías para quienes se vieran involucrados en asuntos de naturaleza punitiva o sancionatoria?. 
En esta primera etapa del desarrollo del Estado moderno - el absolutismo- se concibe que el ius puniendi constituye una potestad inherente a la soberanía del Estado, y que su fundamento, tal como lo describe Hobbes, no está en el hecho de que los súbditos den al soberano el derecho de castigar, sino, en haberse despojado de los suyos (derechos) para conformar el Estado y en consecuencia, éste usa este derecho que le es propio de la forma que le parezca adecuada para la conservación de todos aquellos, siendo en consecuencia nounderecho dado, sino, "dejado a él"10.

En el escenario descrito, el poder se hallaba concentrado en el monarca, en quien convergían todas las atribuciones propias de la soberanía y por lo cual, ante la falta de distinción y separación de funciones, detentaba el ius puniendi sin mayores restricciones y de una única manera, es decir, sin discriminar el ámbito penal o administrativo en el que aquel se materializara.

Lo anterior no significó sin embargo, que el Estado absolutista se quedara estático en su evolución y por ello, bajo la variante ilustrada basada en las ideas iluministas del siglo XVIII, dio pie para el desarrollo de la llamada ciencia de la policía", que determinará la doctrina del gobierno y de la administración al interior del Estado, encaminada a la atención de asuntos de interés colectivo tales como la salubridad pública, el orden moral, religioso y el orden público ${ }^{12}$, dando paso así, a un primer bosquejo de distinción funcional previo a la consolidación del Estado de Derecho propiamente dicho, y estableciendo por primera vez la dualidad en el ejercicio del ius puniendi.

En medio del absolutismo y como reacción en su contra, Locke esboza que el cuerpo político sólo puede ser el resultado del consentimiento de los hombres, que siendo libres, iguales e independientes, convienen en unirse en sociedad para su conservación y seguridad mutua ${ }^{13}$, de lo cual se desprende que el Estado deriva su potestad punitiva, no de que se le "hubiese dejado el derecho de castigar", sino, de la decisión conciente y voluntaria de los hombres de habilitarlo para que de acuerdo con las leyes, se castigue a quienes las infrinjan.

Al respecto plantea: "Mas aunque todo hombre que ha entrado a formar parte de cualquier sociedad civil y se ha convertido en miembro de un Estado ha renunciado a su poder de castigar las ofensas contra la ley de la naturaleza según le dicte su juicio personal, ocurre que, junto con la entrega de ese poder de juzgar que él ha cedido a la legislatura en todos aquellos casos en los que le fue posible recurrir a un magistrado, también ha dado al Estado el derecho de emplear su propia fuerza personal para que se pongan en ejecución los juicios de dicho Estado. Y estos juicios formulados por el Estado son, ciertamente, juicios suyos tanto si son hechos por él mismo como si los formula su representante. Y ahí tenemos el origen del poder legislativo y ejecutivo de la sociedad civil, poder que consiste en juzgar, mediante las leyes, hasta qué punto deben castigarse las ofensas cuando son cometidas dentro del Estado"114

En Rousseau puede leerse que el poder punitivo radica en el pacto social que tiene por finalidad la conservación de los contratantes, y en el reconocimiento que se le hace al Estado de la facultad que tiene para sancionar a quienes transgreden el contrato social ${ }^{15}$, puesto que todos, 
según este autor, han de enajenar totalmente sus derechos a favor de toda la comunidad ${ }^{16}$, bajo la dirección de la voluntad general, y ésta, adoptando la forma de cuerpo político, soberano o Estado", determinará los "dones" ${ }^{18}$ o los derechos que cada individuo habrá de tener, así como las consecuencias derivadas de las transgresiones al derecho social y a las cuales se harán acreedores.

Beccaria plantea que el soberano basa su derecho a castigar los delitos en la necesidad de "defender el depósito de la salud pública de las particulares usurpaciones" ${ }^{19}$, y que la facultad para la determinación de las penas de los delitos "debe residir únicamente en el legislador que representa toda la sociedad unida por el contrato social ${ }^{\prime 20}$.

No obstante las diferencias presentadas entre las apreciaciones de los importantes autores antes citados, existe un punto de encuentro que representa la característica fundamental del ius puniendi, cual es, el hecho de que la potestad punitiva del Estado, de una u otra forma deriva de la autorización o del acuerdo de los miembros de la sociedad, que siendo concientes de la necesidad de establecer mecanismos para garantizar su convivencia y coexistencia, aceptan y reconocen tal facultad como consecuencia lógica de la organización política, y como fundamento para el mantenimiento de un orden social.

Todo lo anterior implica que el Estado sea el depositario y titular de la potestad sancionadora, con independencia de la forma que éste la adquiera o cómo se organice internamente, lo que ha conducido a que en la actualidad se acepte mayoritariamente, que la potestad sancionadora del Estado es una sola, pero que en algunos Estados se admite en una doble dimensión, esto es, la potestad sancionadora penal y la potestad sancionadora administrativa.

Sin embargo, vale la pena anotar que un sector de la doctrina ha planteado en oposición a la tesis de la única potestad sancionadora del Estado, que más bien lo que se presenta es "la coexistencia paralela de dos potestades sancionadoras -la penal y la administrativa" ${ }^{21}$, y que esta última se encuentra relacionada con el concepto de gestión o intervención más que a una tesis policia ${ }^{22}$.

Ese planteamiento aunque no mayoritario, cobra especial relevancia si se tiene en cuenta que incluso se apoya en el cuestionamiento mismo que se hace del "estatocentrismo"que implica la forma como se concibe el ius puniendi en la actualidad, es decir, considerar que el ius puniendi constituye una potestad cuyo único titular es el Estado.

En contra del criterio mayoritario, Alejandro Nieto expone como ejemplo, la potestad punitiva de la comunidad europea, que sin ser un Estado, se halla facultada para ejercerla y que le aporta según su lectura, argumentos que "superan por los cuatro costados ese ius puniendi del Estado que en la dogmática convencional califica con ingenuo estatocentrismo de único" ${ }^{23}$.

Sin desconocer la agudeza de tal observación, en el presente artículo se considera que el hecho de la existencia de organismos supranacionales o internacionales que en algún momento puedan estar dotados de ese poder punitivo supraestatal, no mengua el valor teórico y 
dogmático del ius puniendi como atribución exclusiva del Estado derivada de su propia configuración, por cuanto dicha aseveración halla su fundamento no sólo en el reconocimiento de que en cuanto su origen el ius puniendi es de creación estatal y no supraestatal, sino de que cuando se alude a tal concepción - el ius puniendi-suele hacerse referencia a la innegable facultad que detenta el Estado en abstracto para penar y sancionar a los infractores de cierta normativa penal y administrativa, y que en el contexto de un Estado determinado, solo a él, le está dada tal potestad punitiva.

Es decir, es válido hablar del ius puniendi como atribución estatal, por cuanto generalmente es a este nivel que opera el ejercicio de esa facultad, pero por obvias razones el poder punitivo del Estado está sometido a los límites de su propia soberanía, lo que implica que si bien es cierto el ius puniendi es una noción conceptual abstracta referida al Estado, también lo es, que su concreción se radica en cuanto Estado existe, de lo que resulta que individualmente considerados todos los estados son titulares del poder punitivo, pero ninguno tiene la facultad de ejercerlo por fuera de sus límites territoriales y mucho menos de imponerlo a otros estados.

Ahora bien, resulta apenas obvio que ante la necesidad de interacción interestatal, las relaciones internacionales de toda índole requieren de la creación de una nueva nomenclatura jurídica para establecer las condiciones que las regirán. En este punto, los tratados, los acuerdos, las instituciones y organismos internacionales y supraestatales, se dan como resultado de los acuerdos entre Estados que deciden libremente reconocer en ocasiones ese poder punitivo a organismos supraestatales.

Lo anterior no tiene por qué implicar oposición entre el reconocimiento del ius puniendi como atribución estatal, y la existencia de un ius puniendi de carácter supraestatal, que sí existe, es gracias a la decisión de los Estados partes o miembros de dicha organización de reconocer esa facultad.

De otro lado, si se parte de la base de que el ius puniendi es inherente a la existencia misma del Estado, comoquiera que el poder punitivo ante todo es una forma del poder del Estado, y que ese poder es en sí mismo uno de los elementos fundamentales de éste, el poder punitivo del Estado o ius puniendi resulta ser al interior del Estado, una de las formas de concreción del poder público.

Precisamente con fundamento en lo anterior puede plantearse que el poder punitivo del Estado se verá reflejado en la función constituyente, la función legislativa, la función administrativa, la función jurisdiccional, la función de control, y en general en todas o casi todas las funciones públicas, que de una u otra participan en la concreción del poder público.

Esa apreciación esbozada conduce de manera inevitable a entender que el ius puniendi del Estado en el contexto del Estado de Derecho es normativo, por cuanto sin excepción, las funciones públicas se hallan sometidas al imperio de la ley y su forma de realización en consecuencia, se lleva a cabo por los cauces del derecho, arrojando como resultado en el 
específico caso del poder punitivo del Estado, que todas las actuaciones que tengan por objeto su ejercicio, deban estar representadas en disposiciones jurídicas bien sea, abstractas de facultad, o concretas de aplicación, pero en todo caso será el derecho el lenguaje natural de tal potestad $^{24}$.

Sobre este particular la Corte Constitucional expresó: "Ahora bien, cualquiera sea la ubicación de un órgano u organismo dentro de la estructura general del Estado, es lo cierto que la competencia sancionadora que a él se atribuya ha de tener fundamento en la ley como expresión de la voluntad democrática de los asociados ${ }^{\prime 25}$.

Como corolario de todo lo anterior puede decirse que el ius puniendi o poder punitivo del Estado, es la facultad de la que éste se encuentra investido para determinar qué conductas contrarían o perturban el orden social, y para establecer e imponer las consecuencias sancionatorias, penales o administrativas, derivadas de su trasgresión.

El ejercicio de tal facultad se ve reflejado en prácticamente todas las funciones públicas, de lo que deriva que el ius puniendi no sea una función pública, sino, una potestad del poder público y por ende del Estado mismo, que se concretiza a través de las diversas funciones públicas ${ }^{26}$.

Claro lo anterior, bien vale la pena considerar en el caso específico de Colombia, desde qué perspectiva ha entendido la jurisprudencia nacional el ius puniendidel Estado, y cuáles han sido los principales pronunciamientos emitidos sobre esta materia en los últimos años.

La Corte Suprema de Justicia en providencia del año 1983, en relación con la materia comprensiva del derecho punitivo del Estado señaló que "es una disciplina del orden jurídico que absorbe o recubre como género cinco especies, a saber: el derecho penal delictivo (reato), el derecho contravencional, el derecho disciplinario, el derecho correccional y el derecho de punición por indignidad política (impeachment) ${ }^{127}$.

Por su parte la Corte Constitucional en sentencia T-011 de 1992 hizo las primeras aproximaciones al tema por parte de esta corporación al plantear que "Toda infracción merecedora de reproche punitivo tiene una misma naturaleza, como idénticas son las consecuencias, no obstante que provengan de una autoridad administrativa o jurisdiccional o que tengan origen en las diferencias formales de los trámites rituales. De consiguiente, los principios que rigen todo procedimiento deben necesariamente hacerse extensivos a todas las disciplinas sancionatorias en las que no ha existido un desarrollo doctrinal adecuado sobre esta materia $^{128}$.

En sentencia C-21 4 de 1994, la Corte Constitucional sostuvo que "El poder del Estado, aun cuando concebido como un todo unitario, por la razón obvia de la división y especialización del trabajo se desdobla en una serie de atribuciones, facultades o competencias, institucionalizadas en el ordenamiento constitucional, que se radican en cada una de las ramas del poder público y traducen la existencia de unas funciones, las cuales constituyen los medios o instrumentos necesarios para el cumplimiento de los cometidos estatales. 
La fracción de poder estatal radicada en cabeza de la administración, se manifiesta a través de una gama de competencias o potestades específicas (de mando, ejecutiva o de gestión, reglamentaria, jurisdiccional y sancionadora), que le permiten a aquella cumplir con las finalidades que le son propias" ${ }^{29}$.

En esa misma providencia la Corte señaló que "la potestad punitiva del Estado, como se vio antes, engloba el conjunto de competencias asignadas a los diferentes órganos para imponer sanciones de variada naturaleza jurídica. Por ello, la actuación administrativa requerida para la aplicación de sanciones, en ejercicio de la potestad sancionadora de la administración correctiva y disciplinaria - está subordinada a las reglas del debido proceso que deben observarse en la aplicación de sanciones por la comisión de ilícitos penales ${ }^{\prime \prime 30}$.

En providencia posterior sostuvo la Corte: "La potestad administrativa sancionadora constituye un instrumento de realización de los fines que la Carta atribuye a estas autoridades, pues permite realizar los valores del orden jurídico institucional, mediante la asignación de competencias a la administración que la habilitan para imponer a sus propios funcionarios y a los particulares el acatamiento, inclusive por medios punitivos, de una disciplina cuya observancia contribuye indudablemente a la realización de sus cometidos. Pueden distinguirse por lo pronto diferentes órbitas de acción sancionadora de la administración: así, frente a sus propios servidores opera el derecho disciplinario en sentido estricto, mientras que frente a la generalidad de los administrados se suele hablar en general de derecho correccional ${ }^{3}$.

Mediante sentencia C-616 de 2002, la Corte Constitucional señaló, a más de reiterar lo previsto en la sentencia C-2 14 de 1994, que En razón a su condición de actividad punitiva del Estado, la imposición de sanciones administrativas se encuentra sujeta al artículo 29 de la Constitución que consagra el derecho al debido proceso ${ }^{32}$.

En otra oportunidad, expresó la Corte Constitucional que Conforme lo enseña la jurisprudencia de esta Corporación, el Estado, como titular del ius puniendi, es el llamado a fijar los lineamientos de la política que en materia criminal ha de aplicarse para posibilitar la convivencia pacífica en sociedad y para asegurar la defensa de los valores, derechos y garantías ciudadanas, tomando como referente válido las circunstancias históricas del momento y las diversas situaciones de orden coyuntural que se generan al interior de la comunidad, atribuibles a una dinámica social, política, económica e incluso cultural de permanente cambio y evolución ${ }^{33}$.

En sentencia T-1039 de 2006, la Corte sostuvo que "Como bien ha señalado la jurisprudencia constitucional el Estado puede ejercer el ius puniendi por medio de distintas modalidades jurídicas, entre las cuales se cuenta el derecho disciplinario. Este último hace parte del derecho administrativo sancionador, género que agrupa diversas especies ítales como el derecho contravencional, el derecho correccional, y el propio derecho disciplinario- y en general "pretende garantizar la preservación y restauración del ordenamiento jurídico, mediante la imposición de una sanción que no sólo repruebe sino que también prevenga la realización de 
todas aquellas conductas contrarias al mismo. Se trata, en esencia, de un poder de sanción ejercido por las autoridades administrativas que opera ante el incumplimiento de los distintos mandatos que las normas jurídicas imponen a los administrados y aún a las mismas autoridades públicas ${ }^{1134}$.

Esas providencias judiciales echan de ver que en el derecho colombiano es aceptada la tesis según la cual el poder punitivo del Estado es uno solo, pero que admite dos dimensiones, la penal y la administrativa.

\subsection{De la potestad sancionadora de la administración.}

Planteada y aceptada tesis de la potestad punitiva del Estado en su doble dimensión, corresponde ahora ahondar en el estudio de la potestad sancionadora de la administración.

Según el Diccionario de la Real Academia de la Lengua Española, el término potestad significa dominio, poder, jurisdicción o facultad que se tiene sobre algo ${ }^{35}$.

Sin embargo, desde la perspectiva del derecho administrativo, el vocablo potestad se entiende como una especie del término genérico de poder, por cuanto éste es atributo del Estado, en tanto la potestad se concibe como una prerrogativa inherente al ejercicio de una función ${ }^{36}$.

La potestad sancionadora en este caso se aborda desde la perspectiva de la función administrativa como una prerrogativa que le es inherente, haciendo la aclaración, que en todo caso, en su creación intervienen casi todas las funciones públicas, bien sea otorgándolas dentro del contexto del ordenamiento jurídico, o ejerciéndolas según el principio de legalidad.

Con todo, vale la pena precisar que el origen de la potestad en abstracto, no procede del tráfico jurídico de la creación o innovación de relaciones jurídicas a través de negocios, actos o hechos jurídicos, sino directamente del ordenamiento ${ }^{37}$.

Esta potestad sancionadora es de carácter reglada, lo que se constituye en la primera garantía para evitar el ejercicio arbitrario del poder que en ella se encuentra representado, por cuanto su ejercicio está condicionado a una serie de parámetros normativos encaminados a evitar el abuso y la arbitrariedad, y orientados a la consecución del interés general sin menoscabo de los derechos fundamentales de quienes puedan verse involucrados en un procedimiento sancionador.

El propósito de la potestad sancionadora de la administración no puede ser otro que el bienestar general, el bien común, pero es claro que dentro del contexto del Estado Social de Derecho debe ejercerse con plena observancia de las garantías constitucionales y legales, buscando siempre la consecución de los fines del Estado sin que ello implique la vulneración de los derechos fundamentales, y por el contrario, sean un mecanismo para su defensa. 
En este escenario, el derecho administrativo sancionador se debe presentar como un derecho garantista que permita un perfecto equilibrio entre el control social y el amparo de los derechos ciudadanos.

\subsection{De la justificación de la sanción administrativa.}

En el campo del derecho penal la discusión sobre la justificación de la pena es de vieja data y básicamente la disciplina que se ha encargado de su estudio ha sido la criminología, que tiene como propósito el estudio interdisciplinario y causal-explicativo del delito, el delincuente y la pena, y en relación con ellos, la víctima y la prevención del crimen ${ }^{38}$.

La justificación de la pena pasó por varios estadios, desde la retaliación, la resocialización del delincuente, hasta la protección de los bienes jurídicos mediante la prevención de nuevas ofensas delictivas $^{39}$, y en general la protección del conglomerado social, pero en el ámbito del derecho administrativo sancionador no han sido tan abundantes las propuestas doctrinarias sobre el tema.

Lo primero que debe advertirse es que si bien es cierto tanto el derecho penal como el derecho administrativo sancionador representan las dos facetas del ius puniendi, tal como ya se dijo, también lo es, que obedecen a lógicas distintas que tienen puntos de convergencia, como lo sería la intención de regular conductas sociales, pero con profundos puntos de divergencia.

Debe anotarse que la sanción administrativa se justifica como medida generalmente disuasiva y no represiva, toda vez que el objetivo del Derecho Administrativo Sancionador no puede ser otro que el de evitar llegar a la imposición de sanciones administrativas, puesto que su eficacia depende, no de que las sanciones se impongan, sino de que las infracciones no se cometan y en consecuencia no se tenga que hacer uso de la potestad sancionadora.

Para que esto sea así, es imprescindible que se entienda que el Derecho Administrativo Sancionador debe ser el componente central de una política pública cuyo objetivo fundamental debe estar encaminado a evitar que más que se cometan infracciones, que se eviten los riesgos al interés general o colectivo que se concretan en las infracciones administrativas. Allí, las sanciones administrativas se convierten en la última ratio de la potestad sancionadora.

El éxito del derecho administrativo sancionador está dado por la inexistencia de la necesidad de la imposición de la sanción administrativa, puesto que su principal papel es preventivo, de conformidad con el grado de interés que tenga la administración de intervenir los diversos escenarios sociales.

Por ende la sanción administrativa se justifica como razón última de un conglomerado normativo dispuesto a garantizar el interés general. 


\subsection{De las garantías en el marco del derecho administrativo sancionador}

Cualquier manifestación del poder punitivo del Estado debe estar precedida de una serie de garantías jurídicas de raigambre Constitucional y legal, sin las cuales la prevalencia y respeto de los derechos fundamentales del ciudadano quedaría en entredicho.

La básica regla garantista está conformada por lo que puede denominarse como el macro principio del debido proceso, consagrado en el caso colombiano en el artículo 29 de la carta política y que se aplica por igual a las actuaciones judiciales o administrativas.

El debido proceso tiene como propósito fundamental el respeto de los derechos fundamentales de quien se vea sometido a cualquier tipo de actuación pública, y su rigor debe ser mayor si se está en presencia de una actuación sancionadora como ocurre en el campo penal o administrativo sancionador.

El debido proceso engloba una serie de principios esenciales para la defensa de los ciudadanos ante el poder del Estado, y entre ellos se destacan el principio de legalidad, que lleva implícito a su vez el de reserva de ley de las sanciones administrativas, la tipicidad de las conductas objeto de reproche administrativo, la existencia de un régimen de responsabilidad subjetivo fundamentado en la culpabilidad, la prohibición de la doble sanción administrativa con fundamento en unos mismos hechos, entre otros postulados que aparecen como garantías procesales a los derechos fundamentales de quienes se ven involucrados en asuntos punitivos.

Pero de manera paralela a las garantías procesales (que no solo se agotan en la aplicación del debido proceso a los procedimientos administrativos sancionatorios sino que abarcan también los judiciales), aparecen otras herramientas garantistas como por ejemplo el principio de proporcionalidad.

Este principio de origen doctrinal alemán, se configura como una garantía de los ciudadanos frente a toda actuación de la administración pública que entrañe una restricción al ejercicio de los derechos ${ }^{40}$.

Sin embargo, debe reconocerse que el principio de proporcionalidad no sólo es aplicable frente a la actividad de la administración pública, por cuanto cumple también la función de estructurar el procedimiento interpretativo para la determinación del contenido de los derechos fundamentales que resulta vinculante para el legislador y para la fundamentación de dicho contenido en las decisiones de control de constitucionalidad de las leyes ${ }^{41}$, y también como elemento orientador en la labor hermenéutica llevada a cabo por los jueces cuando de determinar el alcance de los derechos fundamentales se trata.

En el campo del derecho administrativo sancionador este principio exige que exista un equilibrio entre los medios utilizados y la finalidad perseguida, una correspondencia entre la gravedad de la una conducta y la consecuencia punitiva que se le atribuye ${ }^{42}$. 
La aplicación de este principio básico, junto con el debido proceso y los elementos que de él hacen parte, constituyen el eje central de las garantías inherentes al derecho administrativo sancionador, que no puede concebirse como un derecho represivo utilizado para amedrentar a la sociedad, sino, por el contrario, un instrumento de realización del bienestar general.

El derecho administrativo sancionador visto de esta manera, se presenta como un derecho libertario y controlador del ejercicio del poder punitivo del Estado, más encaminado a evitar su arbitrariedad, que diseñado para reprimir, pero que igualmente pretende cumplir un doble papel: de una parte, garantía del ciudadano frente al Estado, de la otra, garantía de la sociedad frente al ciudadano. Todo lo cual implica, que el discurso del garantismo es de hecho plenamente compatible y fundamental para el adecuado papel esta faceta del derecho está llamada a desempeñar en el marco del Estado Social de Derecho.

Por todo lo dicho el derecho administrativo sancionador y el garantismo, constituyen un binomio inseparable en el contexto de un Estado fundado en la protección de los derechos fundamentales.

\section{Referencias Bibliografías}

Beccaria, Cesare. (1994) De los delitos y de las penas. Barcelona, Altaya.

Bernal Pulido, Carlos. (2005) El principio del proporcionalidad y los derechos fundamentales. Madrid. Centro de Estudios Políticos y Constitucionales.

Chevallier, Jean Jacques. (1997) Las Grandes Obras Políticas. Bogotá, Temis.

Fernández Carrasquilla, Juan. (2007) Derecho Penal Liberal del Hoy. Bogotá. Ibáñez.

Ferrajoli, Luigi. (1989) Derecho y Razón. Teoría del Garantismo Penal. Madrid. Trotta.

Ferrajoli, Luigi. (2006) Garantías y Derecho Penal, en Garantismo y Derecho Penal. Trad. Marina Gascón Abellán. Bogotá. Temis.

García de Enterría, Eduardo y TOMÁS RAMÓN FERNANDEZ. (2002) Curso de Derecho Administrativo. Volll. $8^{\mathrm{a}}$ ed. Madrid, Civitas.

García Gómez de Mercado, (2007) Francisco. Sanciones administrativas, Granada, Comares.

García-pablos de Molina, Antonio. (1994) Criminología, 2ª ed., Valencia, Tirant lo Blanch.

GÓMEZ TOMILLO, Manuel. (2008) Derecho Administrativo Sancionador. Parte General, Pamplona, Thomson-Aranzadi. 
Hobbes, Thomas. (1983) Leviatán. Vol I. Madrid, Sarpe.

Kelsen, Hans. (2004) Teoría General del Estado. 1ª ed. México. Coyoacán.

Locke, John. (2006) Segundo Tratado sobre el Gobierno Civil. Madrid. Alianza Editorial.

Marienhoff, Miguel. (1992) Tratado de Derecho Administrativo. T. I. Buenos Aires. Abeledo Perrot. $3^{\mathrm{a}}$ ed.

Nieto García, Alejandro. (1994) Derecho Administrativo Sancionador. $2^{a}$ ed. Madrid, Tecnos.

Ossa Arbelaez, Jaime. (2000) Derecho Administrativo Sancionador, Bogotá, Legis, $1^{\text {a }}$ ed.

Parejo Alfonso, Luciano.(2009) El concepto del Derecho Administrativo. Bogotá, Universidad Externado de Colombia.

Pérez Martínez, Diego. (2005) El principio de proporcionalidad. En Manual de Derecho Administrativo Sancionador. Navarra. Ministerio de Justicia - Thomson Aranzadi.

Rousseau, Jean Jacques. (1973) El Contrato Social. Madrid, Aguilar.

Santamaría Pastor, Juan Alfonso. (2005) Principios de Derecho Administrativo. Vol II. Madrid, Centro de Estudios Ramón Areces.

Corte Suprema de Justicia. MP: Manuel Gaona Cruz. Sentencia No 51 del 14 de abril de 1983. citada en la sentencia C-21 4 de 1994. MP: Antonio Barrera Carbonell

Corte Constitucional. Sentencia C-506 de 1992. MP:

Corte Constitucional. Sentencia C-827 de 2001.

Corte Constitucional. Sala Cuarta de Revisión, 22 de mayo de 1992. MP: Alejandro Martínez Caballero, actor: Joaquín Martínez Vanegas, expediente T-716. Sentencia T-011 de 1992.

Corte Constitucional. Sala Plena, 28 de abril de 1994. MP: Antonio Barrera Carbonell, actor: Álvaro Zapata Burgos, expediente D-394. Sentencia C-21 4 de 1994

Corte Constitucional. Sala Plena, 6 de noviembre de 1996. MP: Alejandro Martínez Caballero, actor: Isidoro Arévalo Buitrago, expediente D-1229. Sentencia C-597 de 1996.

Corte Constitucional. Sala Plena. MP: Sentencia c-616 de 2002.

Corte Constitucional. Sala Plena. MP: Rodrigo Escobar Gil. Sentencia C-762 de 2002. 
'Ferrajoli, Luigi. Derecho y Razón. Teoría del Garantismo Penal. Madrid. Trotta. 1989, p.851.

${ }^{2}$ Ferrajoli, Luigi. Garantías y Derecho Penal, en Garantismo y Derecho Penal. Trad. Marina Gascón Abellán. Bogotá. Temis, 2006. p.3.

${ }^{3}$ Ferrajoli. Derecho y Razón. Op. Cit. p.856

${ }^{4}$ lbid.

${ }^{5}$ Manuel Gómez Tomillo. Derecho Administrativo Sancionador. Parte General, Pamplona, Thomson-Aranzadi, 2008, p. 70. En el mismo sentido: Francisco García Gómez de Mercado. Sanciones administrativas, Granada, Comares, 2007, p. 10. Igualmente: Jaime Ossa Arbelaez. Derecho Administrativo Sancionador, Bogotá, Legis, $1^{\circ}$ ed. 2000, p. 159.

'Jaime Ossa Arbelaez, Derecho Administrativo Sancionador, Bogotá, Legis, $1^{\circ}$ ed. 2000, p. 159.

${ }^{7}$ Corte Constitucional. Sentencia C-506 de 1992. MP:

${ }^{8}$ Juan Alfonso Santamaría Pastor. Principios de Derecho Administrativo. Vol Il. Madrid, Centro de Estudios Ramón Areces, 2005, p. 372.

'Lo que en 1976 fue denominado por algún sector de la doctrina española, tal como lo relata Eduardo García de Enterría, como "Derecho represivo prebeccariano", es decir, anterior a todos los "refinamientos técnicos que el acogimiento de los principios de Beccaria ha supuesto para el Derecho Penal actual". Eduardo García de Enterría y Tomás Ramón Fernandez. Curso de Derecho Administrativo. Vol II. $8^{a}$ ed. Madrid, Civitas, 2002, p. 167.

${ }^{10}$ Thomas Hobbes. Leviatán. Vol I. Madrid, Sarpe, 1983, pp. 31 1-312.

"Luciano parejo alfonso. El concepto del Derecho Administrativo. Bogotá, Universidad Externado de Colombia, 2009, p.139.

${ }^{12}$ Ibid, p. 140.

${ }^{13}$ Jean Jacques Chevallier. Las Grandes Obras Políticas. Bogotá, Temis, 1997, p. 87. 
${ }^{14}$ John Locke. Segundo Tratado sobre el Gobierno Civil. Madrid. Alianza Editorial, 2006, pp. 103-104.

${ }^{15}$ JEAN JACQUES ROUSSEAU. El Contrato Social. Madrid, Aguilar, 1973, pp. 36-37.

${ }^{16}$ lbid, p. 17.

${ }^{17}$ lbid, p. 18.

${ }^{18}$ lbid, p. 37.

${ }^{19}$ CESARE BECCARIA. De los delitos y de las penas. Barcelona, Altaya, 1994, p. 28.

${ }^{20}$ lbid, pp. 29,30.

${ }^{21}$ ALEJANDRO NIETO GARCÍA. Derecho Administrativo Sancionador. $2^{a}$ ed. Madrid, Tecnos, 1994, p. 85.

${ }^{22}$ lbid, p. 96.

${ }^{23}$ Ibid, p. 97.

${ }^{24}$ Sobre este particular bien vale la pena citar a Kelsen, quien plantea que el poder del Estado tiene que ser un poder jurídico. HANS KELSEN. Teoría General del Estado. $1^{a}$ ed. México. Coyoacán, 2004, p. 125.

${ }^{25}$ Corte Constitucional. Sentencia C-827 de 2001.

${ }^{26}$ Para ampliar esta idea se pone como ejemplo el hecho que a través de la función constituyente se haya previsto en la Constitución Política, de manera tácita o expresa tal facultad, lo cual implica la participación de tal función pública en la concreción fundamental del lus puniendi, la función legislativa hace lo propio al establecer el marco normativo en el que se prevén las conductas consideradas perturbadoras del orden social, los procedimientos y las consecuencias de la transgresión normativa. La función jurisdiccional por ejemplo,

${ }^{27}$ Corte Suprema de Justicia. MP: Manuel Gaona Cruz. Sentencia No 51 del 14 de abril de 1983. citada en la sentencia C-21 4 de 1994. MP: Antonio Barrera Carbonell.

${ }^{28}$ Corte Constitucional. Sala Cuarta de Revisión, 22 de mayo de 1992. MP: Alejandro Martínez Caballero, actor: Joaquín Martínez Vanegas, expediente T-716. Sentencia T-011 de 1992. 
${ }^{29}$ Corte Constitucional. Sala Plena, 28 de abril de 1994. MP: Antonio Barrera Carbonell, actor: Álvaro Zapata Burgos, expediente D-394. Sentencia C-214 de 1994.

${ }^{30} \mathrm{lbid}$.

${ }^{31}$ Corte Constitucional. Sala Plena, 6 de noviembre de 1996. MP: Alejandro Martínez Caballero, actor: Isidoro Arévalo Buitrago, expediente D-1229. Sentencia C-597 de 1996.

${ }^{32}$ Corte Constitucional. Sala Plena. MP: Sentencia c-616 de 2002.

${ }^{33}$ Corte Constitucional. Sala Plena. MP: Rodrigo Escobar Gil. Sentencia C-762 de 2002.

${ }^{34}$ Corte Constitucional. MP: Humberto Antonio Sierra Porto, Sentencia T-1039 de 2006

${ }^{35}$ Diccionario de la Real Academia Española. Vigésima segunda edición.

${ }^{36}$ Miguel Marienhoff. Tratado de Derecho Administrativo. T. I. Buenos Aires. Abeledo - Perrot. $3^{\mathrm{a}}$ ed. 1992. p.603,604.

${ }^{37}$ García de Enterría, ob. Cit. P. 444.

${ }^{38}$ Antonio García -pablos De Molina, Criminología, 2a ed., Valencia, Tirant lo Blanch, 1994. pp. 19 y ss.

${ }^{39}$ Juan Fernández Carrasquilla. Derecho Penal Liberal del Hoy. Bogotá. Ibañez, 2007. p. 183.

${ }^{40}$ Diego Pérez Martínez. El principio de proporcionalidad. En Manual de Derecho Administrativo Sancionador. Navarra. Ministerio de Justicia - Thomson Aranzadi. 2005. p 245.

${ }^{41}$ CARLOS BERNAL PULIDO. El principio del proporcionalidad y los derechos fundamentales. Madrid. Centro de Estudios Políticos y Constitucionales. 2005. p.77.

${ }^{42}$ lbid. 